\title{
The Survey of Factors Affecting Pap Smears Based on Health Belief Model in Health Centers in Fasa, Fars Province, Iran
}

\author{
Ali Khani Jeihooni ${ }^{1,}$; Seyyd Mansour Kashfi ${ }^{2}$; Mina Bahmandost ${ }^{1}$; Seyyd Hannan Kashfi ${ }^{3}$ \\ ${ }_{1}^{1}$ Department of Public Health, Fasa University of Medical Sciences, Fasa, IR Iran \\ ${ }^{2}$ Department of Public Health, Research Center for Health Sciences, School of Health, Shiraz University of Medical Sciences, Shiraz, IR Iran \\ ${ }^{3}$ Larestan School of Nursing, Shiraz University of Medical Sciences, Shiraz, IR Iran \\ *Corresponding author: Ali Khani Jeihooni, Department of Public Health, Fasa University of Medical Sciences, Fasa, IR Iran. Tel: +98-9175328065, E-mail: khani_1512@yahoo.com \\ Received: November 24, 2014; Accepted: June 7, 2015
}

\begin{abstract}
Background: Cervical cancer is the second most common cancer among women in the world and the most frequent in developing countries. Secondary prevention, achieved through Pap smear testing, is the single most effective tool in reducing deaths due to cervical cancer.

Objectives: The aim of this study was to assess factors affecting Pap smears in women based on the Health Belief Model in health centers of Fasa, Iran.

Patients and Methods: This cross-sectional study comprised a total of 200 randomly selected married women who referred to health centers in Fasa, Iran. The participants responded to the standard questionnaire. The data obtained were analyzed using SPSS 18.

Results: In this study, approximately $25 \%$ of the subjects had a history of the test. The mean score of all health belief model-related perceived variables including susceptibility, severity, benefits and barriers in patients with a history of the test was higher than those without a history. Analyzing the data using independent t-test showed a significant difference between the mean scores of all HBM structures with performing Pap test in patients with a history of the test. The most important reason for performing the Pap test by subjects was the health professionals' advice (84\%), and the main reason for not performing the test by subjects was their belief that they are not susceptible to cancer.

Conclusions: Women's health care professionals play effective roles in informing women about factors related to cervical cancer screening. According to the results, it would be beneficial to design strategies for reducing barriers to Pap smear test among women.

Keywords: Women's Health; Papanicolaou Test; Cervical Cancer; Health Belief Model
\end{abstract}

\section{Background}

Cancer refers to more than 20 various types of diseases resulting from uncontrolled growth and proliferation of cells in the body. It is influenced by various environmental and genetic factors and is associated with multiple physical symptoms and complaints (1). Cancer can occur anywhere in the body and implicate all the cells (2). In 2003, in our country, 38,468 cases of cancer were reported of which $56.1 \%$ were males and $43.8 \%$ females. Next to breast cancer, cervical cancer is the most common cancer among women in the world and is the third most frequent cancer in Iran $(1,3)$. Cervical cancer, although largely preventable, is still the most prevalent cause of death among women (4). Each year more than 288 million women around the world die of cervical cancer (3). The geographical distribution of this type of cancer shows that 4 to 45 individuals in 100 women have cervical cancer with the highest rates being in Africa, Latin America, Asia, Europe, and America. Eighty percent of people are diagnosed with cervical cancer in developing countries (5). In Iran, $2.34 \%$ of all women were afflicted with cervical cancer in 2003 (1).
In the early stages, cervical cancer can be diagnosed by Pap test, which is the most successful public health intervention program to prevent and control cancer $(6,7)$. Pap test is a simple, cheap and uncomplicated method in screening for cervical cancer (8). Since 1950, Pap test has been successful in reducing the incidence of cervical cancer by $79 \%$ and mortality by $70 \%$ (9). Also, the implementation of screening programs in a few countries for 5 years showed that Pap test could reduce the mortality rate of cervical cancer by $60 \%$ (10). Before the development of Pap test, 25 deaths from cervical cancer per 100,000 cases was reported in the US which was similar to the rates reported for some developing countries (11). Recommendations on when to start screening and how long and how far to continue varies in different countries, which can be attributed to factors such as the prevalence of disease in different regions and cost-effectiveness of screening methods (12). The American college of obstetricians and gynecologists (ACOG) recommends starting cervical cancer screening 3 years after initiation of sexual intercourse followed by rou-

Copyright @ 2015 , Health Policy Research Center, Shiraz University of Medical Sciences. This is an open-access article distributed under the terms of theCreative Commons Attribution-NonCommercial 4.0 International License (http://creativecommons.org/licenses/by-nc/4.0/) which permits copy and redistribute the material just in noncommercial usages, provided the original work is properly cited. 
tine screenings every 2 - 3 years (13). The health belief model (HBM), which was used as the theoretical framework for this study, includes several basic structures that predicts why people take preventive actions, why they seek screening and how they control their disease conditions. This model was mainly developed based on disease prevention and the behaviors adopted to avoid the chain of illness and disease (14). It is one of the most precise models for predicting health-related behaviors and patterns of belief and attitude (15). Based on HBM, a person should believe that he/she is susceptible to a disease such as cervical cancer (perceived susceptibility), understand the depth and seriousness of the risk of complications in his/her life (perceived severity), deem suggested actions like the Pap test as beneficial in reducing the risk of their disease (perceived benefits) and in overcoming inhibiting factors such as cost of operation and pain (Perceived barriers). Although the Pap test has been used since 1991 in the health system of our country and is considered as an effective and inexpensive screening test for cervical cancer, various studies $(12,13)$ indicate that the test is not welcome. The present study was conducted to investigate the factors influencing Pap test administration based on the HBM among women in health centers in Fasa.

\section{Objectives}

The aim of this study was to assess factors affecting Pap smears in women based on health belief model in health centers of Fasa, Iran.

\section{Patients and Methods}

This cross-sectional study was carried out on 200 women covered by health centers in Fasa, comprising women married for at least 6 months. Exclusion criteria were lack of informed consent or unwillingness to participate in the study. The data collection instrument was a questionnaire designed by the researcher and completed by interviews involving low-literate or illiterate participants, and self-report. The questionnaire was prepared in four sections. Part one included 5 questions on demographic characteristics. Part two involved 12 questions with three options (yes, no, I do not know) for measuring knowledge. Part three contained 22 questions about the constructs of the HBM (12 questions for perceived benefits and barriers, 10 questions for perceived susceptibility and severity). Part four included two open questions about the reasons for doing and avoiding a Pap test and finally part five included a checklist for verifying the participants' taking or not taking the Pap test reported by the Midwifery and Family Health Unit in each center. Regarding questions on knowledge, the participants scored 1 point for each correct answer and 0 for wrong responses. For perceived susceptibility, severity, barriers and interests, the questions were scored based on a standard 5-point Likert scale ranging from strongly disagree to strongly agree, indicating 0 for strongly disagree, 1 for disagree, 2 for neither agree nor disagree, 3 for agree, and 4 for strongly agree. Content validity was used to assess the validity of the questionnaire. The questionnaire was developed based on HBM and the related literature and was reviewed by 10 academics of midwifery and health education in Fasa and Shiraz University of Medical Sciences. The faults and ambiguities in the questionnaire were removed according to their comments and the validity was verified. To determine the reliability of the questionnaire, Cronbach's alpha was applied for piloted results on 20 women with similar demographic characteristics. Cronbach's alpha was $85 \%$ for knowledge questions and $82 \%$ for the HBM constructs. As for sampling, Fatemiyeh center was chosen randomly from among urban health centers in Fasa. The population covered by the center was homogenous in terms of cultural characteristics. Next, via systematic sampling, a sample of 200 women was chosen from among the population. To complete the questionnaires, the research team invited the participants to the center by phone calls. Having briefed the participants about the study objectives, and obtaining their informed consent, the questionnaires were distributed among them by the researcher at the site. Data were analyzed using SPSS 18 and descriptive statistics, t-test, ANOVA and logistic regression with $\mathrm{P}<0.05$ considered as significant.

\section{Results}

The participants aged from 30 - 40 years with mean age $38.9 \pm 6.21$ years and the education being mostly at middle and secondary school levels. Also, 95\% of the participants were housewives and the others were working. In addition, $95 \%$ of the subjects were covered by insurance services (Table 1). There was no significant relationship between knowledge and HBM constructs on the one hand and age $(P=0.012)$, education level $(P=0.101)$ and number of children $(\mathrm{P}=0.09)$ on the other. In addition, there was no significant difference between the mean scores of knowledge and HBM constructs with the employment ( $P$ $=0.082)$ and insurance status $(\mathrm{P}=0.071)$ among participants (Table 1).

In this study, approximately $25 \%$ of the subjects had a history of the test. The mean score of all HBM constructs (perceived susceptibility, severity, benefits and barriers) in patients with a history of test was higher than in those lacking a history. Analyzing the data using independent t-test showed a significant difference between the mean scores of all HBM structures with performing Pap test in patients with a history of the test $(\mathrm{P}<0.05$, Table 2$)$.

As shown in Table 3, the most important reason for performing the Pap test by subjects was health professionals' advice (84\%), and the most important aspect for not performing the test by subjects was their denial of susceptibility to cancer, so called low perceived susceptibility $(82 \%)$. 
Khani Jeihooni A et al.

Table 1. Mean and Standard Deviation of HBM Constructs Based on Demographic Variables ${ }^{\text {a }}$

\begin{tabular}{|c|c|c|c|c|c|c|}
\hline Variable & Subjects & Knowledge & Susceptibility & Severity & Benefits & Barriers \\
\hline \multicolumn{7}{|l|}{ Age, $y$} \\
\hline $30-40$ & $120(60)$ & $9.32 \pm 1.21$ & $8.7 \pm 2.32$ & $8.7 \pm 1.78$ & $11.38 \pm 3.29$ & $12.42 \pm 3.91$ \\
\hline Over 40 & $80(40)$ & $9.55 \pm 1.11$ & $9.64 \pm 2.21$ & $11.54 \pm 1.92$ & $12.91 \pm 3.77$ & $13.11 \pm 2.94$ \\
\hline \multicolumn{7}{|l|}{ Education level } \\
\hline Illiterate & $5(2.5)$ & $9.02 \pm 1.52$ & $8.25 \pm 1.59$ & $11.73 \pm 2.15$ & $12.32 \pm 3.65$ & $12 \pm 3.44$ \\
\hline Primary education & $25(12.5)$ & $9.28 \pm 1.44$ & $9.67 \pm 1.94$ & $11.97 \pm 2.83$ & $13.1 \pm 4.31$ & $12.78 \pm 3.45$ \\
\hline Secondary education & $100(50)$ & $9.34 \pm 1.73$ & $8 \pm 1.84$ & $11.10 \pm 2.6$ & $13.50 \pm 3.21$ & $13.47 \pm 3.97$ \\
\hline Diploma & $55(27.5)$ & $9.50 \pm 1.44$ & $9.25 \pm 1.75$ & $11.10 \pm 2.38$ & $13.78 \pm 4.41$ & $12.65 \pm 4.85$ \\
\hline College & $15(7.5)$ & $9.78 \pm 1.21$ & $9.37 \pm 2.28$ & $12 \pm 2.52$ & $13.78 \pm 4.38$ & $13.54 \pm 3.12$ \\
\hline \multicolumn{7}{|l|}{ No. of children } \\
\hline None & $10(5)$ & $9.78 \pm 1.85$ & $9.67 \pm 2.54$ & $9.17 \pm 2.30$ & $13.54 \pm 4.52$ & $12.15 \pm 3.96$ \\
\hline $1-2$ & $125(62.5)$ & $9.20 \pm 1.85$ & $9.48 \pm 1.74$ & $8.50 \pm 1.70$ & $13.17 \pm 4.65$ & $12.52 \pm 3.45$ \\
\hline More than 2 & $65(32.5)$ & $9 \pm 1.45$ & $11.25 \pm 2.52$ & $8.80 \pm 2.51$ & $13.25 \pm 4.19$ & $13.59 \pm 3.82$ \\
\hline \multicolumn{7}{|l|}{ Employment } \\
\hline Housewife & $190(95)$ & $8.25 \pm 1.55$ & $9.55 \pm 2.24$ & $8.45 \pm 2.90$ & $12.95 \pm 4.66$ & $12.12 \pm 3.26$ \\
\hline Working & $10(5)$ & $7.67 \pm 1.35$ & $9.85 \pm 1.34$ & $8.54 \pm 1.39$ & $13.50 \pm 4.41$ & $8.57 \pm 2.78$ \\
\hline \multicolumn{7}{|l|}{ Test history } \\
\hline Yes & $190(95)$ & $7.97 \pm 1.45$ & $11.28 \pm 2.45$ & $8.41 \pm 2.30$ & $14.14 \pm 4.41$ & $13.95 \pm 4.65$ \\
\hline No & $10(5)$ & $7.42 \pm 1.45$ & $11.34 \pm 1.55$ & $8.35 \pm 1.82$ & $13.55 \pm 4.14$ & $12.21 \pm 4.35$ \\
\hline \multicolumn{7}{|l|}{ Insurance status } \\
\hline Yes & $190(95)$ & $8.72 \pm 1.26$ & $10.7 \pm 2.33$ & $10.87 \pm 1.31$ & $12.59 \pm 3.49$ & $11.96 \pm 4.31$ \\
\hline No & $10(5)$ & $9.35 \pm 2.21$ & $9.8 \pm 2.42$ & $9.8 \pm 2.79$ & $12.48 \pm 3.59$ & $12.52 \pm 3.51$ \\
\hline
\end{tabular}

$\mathrm{a}$ The valves are presented as Mean \pm SD or No. (\%).

Table 2. Mean of HBM Construct Model Spectra and Pap Test Performance in Patients With and Without Test History

\begin{tabular}{|c|c|c|c|c|c|c|}
\hline \multirow[t]{2}{*}{ Variable } & \multicolumn{2}{|c|}{ Subjects Without Test History $(n=148)$} & \multicolumn{2}{|c|}{ Subjects With Test History $(n=52)$} & \multirow[t]{2}{*}{ Total Number } & \multirow[t]{2}{*}{ P Value } \\
\hline & $\begin{array}{c}\text { Pap Test } \\
\text { Performance }\end{array}$ & Mean \pm SD & $\begin{array}{c}\text { Pap Test } \\
\text { Performance }\end{array}$ & Mean \pm SD & & \\
\hline Susceptibility & $8.12(0.75)$ & $8.35 \pm 0.95$ & $11.35(0.75)$ & $8.65 \pm 0.45$ & 200 & 0.012 \\
\hline Severity & $9.14(0.87)$ & $9.45 \pm 0.65$ & $12.34(0.65)$ & $9.85 \pm 0.25$ & 200 & 0.025 \\
\hline Benefits & $9.50(0.95)$ & $12.10 \pm 0.75$ & $15.10(0.75)$ & $12.45 \pm 0.55$ & 200 & 0.001 \\
\hline Barriers & $13.25(0.58)$ & $11.95 \pm 0.85$ & $9.35(0.95)$ & $12.57 \pm 0.65$ & 200 & 0.011 \\
\hline
\end{tabular}

Table 3. Reasons for Performing or Not Performing Pap Test ${ }^{a}$

\begin{tabular}{|c|c|}
\hline Type of Reasons & Values \\
\hline \multicolumn{2}{|l|}{ Reasons for performing Pap test } \\
\hline Health professionals' (doctor, midwife, ...) advice & $168(84)$ \\
\hline Using contraceptive pills and vials & $120(60)$ \\
\hline Early diagnosis of uterine problems & $122(61)$ \\
\hline Advice by friends and acquaintances & $80(40)$ \\
\hline Being diagnosed with vaginal tract diseases & $82(41)$ \\
\hline No specific reason & $62(31)$ \\
\hline \multicolumn{2}{|l|}{ Reasons for not performing Pap test } \\
\hline Denial of susceptibility to cancer & $164(82)$ \\
\hline Fearful of having positive pap test & $110(55)$ \\
\hline Lack of knowledge about the pap test & $90(45)$ \\
\hline Young age & $80(40)$ \\
\hline No specific reason & $50(25)$ \\
\hline Natural method of contraception & $54(27)$ \\
\hline
\end{tabular}


Khani Jeihooni A et al.

\begin{tabular}{|c|c|c|c|c|c|c|}
\hline Variables & P Value & \multicolumn{3}{|c|}{$\mathbf{B}^{\mathrm{b}}$} & \multicolumn{2}{|l|}{$\mathrm{SE}^{\mathrm{c}}$} \\
\hline Employment & 0.122 & \multicolumn{3}{|c|}{0.794} & \multicolumn{2}{|l|}{0.021} \\
\hline Education level & 0.0413 & \multicolumn{3}{|c|}{0.026} & \multicolumn{2}{|l|}{0.04} \\
\hline Age & 0.024 & \multicolumn{3}{|c|}{0.05} & \multicolumn{2}{|l|}{0.06} \\
\hline Perceived susceptibility & 0.02 & \multicolumn{3}{|c|}{0.1} & \multicolumn{2}{|l|}{0.055} \\
\hline Perceived severity & 0.224 & \multicolumn{3}{|c|}{0.047} & \multicolumn{2}{|l|}{0.045} \\
\hline Perceived benefits & 0.018 & \multicolumn{3}{|c|}{0.02} & \multicolumn{2}{|l|}{0.025} \\
\hline Perceived barriers & 0.613 & \multicolumn{3}{|c|}{0.01} & \multicolumn{2}{|l|}{0.014} \\
\hline Knowledge & 0.028 & \multicolumn{3}{|c|}{0.007} & \multicolumn{2}{|l|}{0.03} \\
\hline \multicolumn{7}{|c|}{$\begin{array}{l}\mathrm{a} \text { Dependent variable }=\text { Pap test performance }\left(\mathrm{R}^{2} \text { adjusted }=0.042\right) . \\
\mathrm{b} \mathrm{B}=\text { Non-standardized regression coefficient. } \\
{ }^{\mathrm{C}} \mathrm{SE}=\text { Standard error. }\end{array}$} \\
\hline \multicolumn{2}{|l|}{ Perceived Barriers Questions } & $\begin{array}{c}\text { Strongly } \\
\text { Agree }\end{array}$ & Agree & $\begin{array}{l}\text { Neither Agree or } \\
\text { Disagree }\end{array}$ & $\begin{array}{l}\text { Strongly } \\
\text { Disagree }\end{array}$ & Disagree \\
\hline \multicolumn{2}{|c|}{ Sampling is difficult and I hate all kind of tests. } & $50(25)$ & $45(22.5)$ & $35(17.5)$ & $40(20)$ & $30(15)$ \\
\hline \multicolumn{2}{|c|}{ I do not have time for a Pap smear. } & $12(6)$ & $30(15)$ & $35(17.5)$ & $85(42.5)$ & $38(19)$ \\
\hline \multicolumn{2}{|c|}{ In case I have cervical cancer I prefer not to know about it. } & $60(30)$ & $70(35)$ & $30(15)$ & $30(15)$ & $10(5)$ \\
\hline \multicolumn{2}{|c|}{ Disease and cancer are parts of Divine destiny. } & $50(25)$ & $70(35)$ & $35(17.5)$ & $35(17.5)$ & $10(5)$ \\
\hline \multicolumn{2}{|c|}{ Reluctant to have Pap test for fear of having positive result } & $60(30)$ & $80(40)$ & $20(10)$ & $20(10)$ & $20(10)$ \\
\hline \multicolumn{2}{|c|}{$\begin{array}{l}\text { Doubting the diagnostic efficacy of Pap test and prevention } \\
\text { of cervical cancer }\end{array}$} & $15(7.5)$ & $30(15)$ & $50(25)$ & $80(40)$ & $25(12.5)$ \\
\hline
\end{tabular}

a All values are presented as No. (\%).

Regression analysis was used to evaluate the predictive ability of variables affecting the Pap test performance. The results showed that age, education level and the HBM constructs explain a total of $35 \%$ of variance in test performance behavior. The results showed significant predictive ability of age, education level, knowledge, perceived benefits and perceived susceptibility, where the variables of perceived interest and perceived susceptibility had the highest rate of predictive ability followed by perceived barriers, knowledge, perceived severity, age and education level (Table 4).

The most important barriers to performing Pap test by participants of this study were fear of positive Pap test, misconception about health and the difficulty of performing the test (Table 5).

\section{Discussion}

The current study investigates the relationship between HBM constructs and Pap test performance. The results showed that HBM constructs alongside age, education level and knowledge account for $35 \%$ of variance in Pap tests performance behavior. This is consistent with the results of Mazloomy et al.'s (16) study of diabetic patients in which HBM constructs explained $28.2 \%$ of the variance in self-care behavior. In the study by Karimy et al. (17), the constructs predicted $38.5 \%$ of the observed dispersion in breast self-examination (BSE) behavior. According to the study by Cooper et al. (18) HBM has a better performance than other models for assessing screening behaviors among Asians because of the positive relationship between some of these constructs and the desired behavior in this area. In this study, about $25 \%$ of the samples had a history of Pap test. This low rate can be explained by the mean scores obtained from HBM constructs. In addition, regarding perceived benefits, which was the most important predictor of Pap test performance among subjects, the mean test score for subjects with Pap test history was 15 and that for subjects without Pap test history was 9 out of 24. This shows the importance of subjects' perception of benefits of a program and its screening method. The reason given for performing the Pap test by $61 \%$ of the subjects was early detection and treatment of cervical problems. The perceived benefits in order of importance were the Pap test's efficiency in early detection and treatment of cervical cancer, simplicity and convenience of performing the test and the information obtained from Pap test on the health status.

The results showed that the mean score for perceived barriers in patients without a history of Pap test was higher than in those with a history of Pap test. In patients without a history of Pap test, the most important perceived barriers included fear of the result, attributing 
the disease to destiny, misgiving about the Pap test, the difficulty and uncertainty about diagnostic efficacy of the test.

Studies conducted by Maaita and Barakat in Jordan (19) Holroyd et al. in China (20) and Fernandez-Esquer on Mexican American women (21) showed that apprehension about the result of Pap test and skepticism about cancer treatment were major barriers for performing a Pap test. The findings of this study regarding the relationship between perceived benefits and barriers and performing a Pap test were consistent with those of the study conducted by Allahverdipour and Emami on Iranian women (22), Wong et al. in Malaysia (23), Mandelblatt and Yabroff on women in the US (24) and a report by Markovic et al. from Serbia (25). In addition, the results were consistent with the study by Trieu et al. (14), on exploring the causes of HIV testing among American female students based on the HBM, research of Lamyian et al. (26) on Iranian women's performance in BSE and study conducted by Ratanasuwan et al. (27) in Thailand on the relationship between HBM constructs and the students' physical activity. Based on the HBM, A person with a desired level of perceived susceptibility and severity would not necessarily accept any health advice, unless its potential benefits outweigh its barriers, as perceived well by him/her (17). In this study, the most important reason for performing Pap test was the subjects' belief that they were not prone to cervical cancer, reflected by their low perceived susceptibility, indicated by their mean score of 8.50 out of 20 .

The perceived susceptibility was the most important predictor of Pap test performance followed by perceived benefits. This should be considered in planning for education and counseling for Pap test. Researchers believe that to motivate people to take a particular health care action, require that he/she is susceptible to or have already been affected by the influence of the disturbing force. Health care educators must explain the probability of negative consequences and risks of the disease for clients in an attempt to increase their perceived susceptibility (15). In this study, the mean score on perceived severity in subjects with a history of Pap test was higher than that of subjects without such a history. The findings regarding the relationship between constructs of perceived susceptibility and perceived severity with Pap test performance in women were consistent with those of other studies $(13,28-30)$. A relationship was observed between perceived susceptibility and perceived severity with other health behaviors in other studies including breast self-examination behavior in women (31), female students' performance in HIV testing (14) and mammography (32). In this study, subjects with a history of Pap test had higher scores on knowledge. This finding was consistent with those of other studies $(13,22,33,34)$. However, it was inconsistent with the results of the study by Holroyd et al. on Chinese women (20). The mean knowledge score of 8.5 out of 12 showed a good knowledge of the subjects. However, there was no significant relationship between age and education level of the study population and their Pap test performance. This result was in agreement with the findings of Tabeshian and Firoozeh in Isfahan (35). However, it was contrary to those of Khojasteh in Zahedan (36) who found a significant correlation between education level and knowledge of Pap test. The knowledge of women about Pap test was reported to be low by other studies $(37,38)$ which were not consistent with our results.

The results of this study showed a positive relationship between HBM constructs and Pap test performance. Therefore, other aspects should be considered in addition to increasing the knowledge and awareness of women about Pap test. These include enhancing the subjects' perceived susceptibility and perceived interests and reducing their false beliefs about cancer which is a barrier to performing the Pap test. These measures should be kept in mind in setting the goals for developing and implementing successful educational programs.

\section{References}

1. Ministry of health and medical education.. [National Report on Cancer Registration 2003].Tehran: Ministry of health and medical education; 2005.

2. Park JE, Park K. Park's Textbook of Preventive and Social Medicine.: Banarasidas Bhanot; 1991.

3. Ponten J, Adami HO, Bergstrom R, Dillner J, Friberg LG, Gustafsson L, et al. Strategies for global control of cervical cancer. Int J Cancer. 1995;60(1):1-26.

4. O'Meara AT. Present standards for cervical cancer screening. Curr Opin Oncol. 2002;14(5):505-11.

5. Verschraegen CF, Padilla-Paz LA, Smith HO. New strategies in the prevention and treatment of cervical cancer. Internet J Oncol. 2004;2(1).

6. Baheiraei A. [Preventive measures of cervical cancer].Iran: Boshra; 1997.

7. Mukherjee GG, Surveen C. Current Obstetrics and Gynaecology.New Delhi: Jaypee Brothers Medical Publishers; 2007.

8. WHO.. Pap cytology Screening: Most of the benefits repead press release.: WHO; 1995.

9. Addis LB, Hatch KD, Berek JS. Intraepithelial Disease of the Cervix Vagina and Vulva. In: Berek JS, Novak E editors. Berek and Novak's gynecology.. Philadelphia: Lippincott Williams \& Wilkins; 2002.

10. Coughlin SS, King J, Richards TB, Ekwueme DU. Cervical cancer screening among women in metropolitan areas of the United States by individual-level and area-based measures of socioeconomic status, 2000 to 2002. Cancer Epidemiol Biomarkers Prev. 2006;15(11):2154-9.

11. Alam M, Alizadeh SM, Aflatoonian MR, Azizzadeh M. [Knowledge, Attitude and Practice of Behvarzes Working in Healthcare].J Hor mozgan University Medi Sci. 2007;10(4):379-86.

12. Beckmann C, Ling F, Herbert W, Laube D, Smith R, Barzasky B. Obstetrics and Gynecology. 13 edBaltimor: Williams \& Wilkins; 2000.

13. Yakhforoushha A, Solhi A, Ebadiaza F. [The Effect of Health Education Via Health Belief Model on Knowledge and Attitude of Healthy Voluntaries About Pap Smear in Urban Centers Gazvin].J Nurs Midwif. 2008;18(63):24-31.

14. Trieu SL, Naomi NM, Marshak HH, Males MA, Bratton SI. Factors associated with the decision to obtain an HIV test among Chinese/Chinese American community college women in Northern California. Califor J Health Promo. 2008;6(1):111-27.

15. Karimi M, Ghofranipour FA, Heydarnia AR. [The effect of health education based on health belief model on preventive actions of AIDS on addict in Zarandieh]. J Guilan Univ Med Sci. 2009;18(70):64-73.

16. Mazloomy MS, Mehri A, Morowatisharifabad MA. [The Relation- 
ship of Health Behavior with Self-esteem and Self-efficacy in Students of Yazd Shahid Sadooghi University of Medical Sciences]. Strides Dev Med Educ. 2006;32(111-7)

17. Karimy M, Niknami SH, Shokravi FA, Shamsi M. [The Relationship of Breast Self-examination with Self-esteem and Perceived Benefits/Barriers of Self-efficacy in Health Volunteers of Zarandieh City]. Iranian J Bre Dis. 2010;2(2):14-8.

18. Cooper M, Loue S, Lloyd LS. Perceived susceptibility to HIV infection among Asian and Pacific Islander women in San Diego. $J$ Health Care Poor Underserved. 2001;12(2):208-23.

19. Maaita M, Barakat M. Jordanian women's attitudes towards cervical screening and cervical cancer. $J$ Obstet Gynaecol. 2002;22(4):421-2.

20. Holroyd E, Twinn S, Adab P. Socio-cultural influences on Chinese women's attendance for cervical screening. J Adv Nurs. 2004;46(1):42-52.

21. Fernandez-Esquer ME, Espinoza P, Ramirez AG, McAlister AL. Repeated Pap smear screening among Mexican-American women. Health Educ Res. 2003;18(4):477-87.

22. Allahverdipour H, Emami A. Perceptions of cervical cancer threat, benefits, and barriers of Papanicolaou smear screening programs for women in Iran. Women Health. 2008;47(3):23-37.

23. Wong LP, Wong YL, Low WY, Khoo EM, Shuib R. Cervical cancer screening attitudes and beliefs of Malaysian women who have never had a pap smear: a qualitative study. Int J Behav Med. 2008;15(4):289-92.

24. Mandelblatt JS, Yabroff KR. Breast and cervical cancer screening for older women: recommendations and challenges for the 21st century. JAm Med Womens Assoc. 2000;55(4):210-5.

25. Markovic M, Kesic V, Topic L, Matejic B. Barriers to cervical cancer screening: a qualitative study with women in Serbia. Soc Sci Med. 2005;61(12):2528-35.

26. Lamyian M, Hydarnia A, Ahmadi F, Faghihzadeh S, Aguilar-Vafaie ME. Barriers to and factors facilitating breast cancer screening among Iranian women: a qualitative study. East Mediterr Health J. 2007;13(5):1160-9.

27. Ratanasuwan T, Indharapakdi S, Promrerk R, Komolviphat T, Thanamai Y. Health belief model about diabetes mellitus in Thailand: the culture consensus analysis.J Med Assoc Thai. 2005;88(5):623-31.
28. Abotchie PN, Shokar NK. Cervical cancer screening among college students in ghana: knowledge and health beliefs. Int J Gynecol Cancer. 2009;19(3):412-6.

29. Burak LJ, Meyer M. Using the Health Belief Model to examine and predict college women's cervical cancer screening beliefs and behavior. Health Care Women Int. 1997;18(3):251-62.

30. Barata PC, Mai V, Howlett R, Gagliardi AR, Stewart DE. Discussions about self-obtained samples for HPV testing as an alternative for cervical cancer prevention. J Psychosom Obstet Gynaecol. 2008;29(4):251-7.

31. Karimy M, Hasani M, Khorram R, Ghafari M, Niknami S. [The Effect of Education Based on of Health Belief Model on Breast Self Examination in the Health Volunteers in Zarandieh]. Zahedan J Res Med Sci . 2008;10(4):79-87.

32. Hatefnia E, Niknami S, Mahmoodi M, Ghofranipour G, Lamyian M. The Effect of Health Education Based on Health Belief Model on Mammography and Breast Cancer.J Kermanshah Univ Med Sci .2010;14(1):42-50.

33. Selvin E, Brett KM. Breast and cervical cancer screening: sociodemographic predictors among White, Black, and Hispanic women. Am J Public Health. 2003;93(4):618-23.

34. Katz SJ, Hofer TP. Socioeconomic disparities in preventive care persist despite universal coverage. Breast and cervical cancer screening in Ontario and the United States. JAMA. 1994;272(7):530-4.

35. Tabeshian A, Firoozeh F. [The Effect of Health Education on Performing Pap Smear Test for Prevention of Cervix Cancer in Teachers of Esfehan City]. J Azad Univ Tehran Med Branch. 2009;19(1):35-40.

36. Khojasteh F. [Knowledge, Attitude and Practice of Women's About Pap Smear\& Cervix Cancer in Urban Centers Zahedan]. J Ahvaz Univ Med Sci. 2004;41(4):2-9.

37. Lee MC. Knowledge, barriers, and motivators related to cervical cancer screening among Korean-American women. A focus group approach. Cancer Nurs. 2000;23(3):168-75.

38. Wong LP, Wong YL, Low WY, Khoo EM, Shuib R. Knowledge and awareness of cervical cancer and screening among Malaysian women who have never had a Pap smear: a qualitative study. Singapore Med J. 2009;50(1):49-53. 